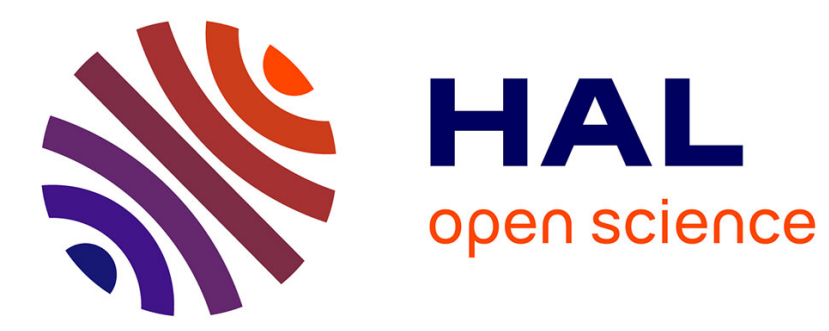

\title{
Fragmentation patterns of chromophore-tagged peptides in visible laser induced dissociation
}

Lény Garcia, Jérôme Lemoine, Philippe Dugourd, Marion Girod

\section{To cite this version:}

Lény Garcia, Jérôme Lemoine, Philippe Dugourd, Marion Girod. Fragmentation patterns of chromophore-tagged peptides in visible laser induced dissociation. Rapid Communications in Mass Spectrometry, 2017, 31 (23), pp.1985-1992. 10.1002/rcm.7984 . hal-01646160

\section{HAL Id: hal-01646160 \\ https://hal.science/hal-01646160}

Submitted on 4 Sep 2020

HAL is a multi-disciplinary open access archive for the deposit and dissemination of scientific research documents, whether they are published or not. The documents may come from teaching and research institutions in France or abroad, or from public or private research centers.
L'archive ouverte pluridisciplinaire HAL, est destinée au dépôt et à la diffusion de documents scientifiques de niveau recherche, publiés ou non, émanant des établissements d'enseignement et de recherche français ou étrangers, des laboratoires publics ou privés. 


\section{Fragmentation patterns of Chromophore-Tagged Peptides}

\section{in Visible Laser Induced Dissociation.}

Lény Garcia ${ }^{a}$, Jérôme Lemoine ${ }^{a}$, Philippe Dugourd ${ }^{b}$ and Marion Girod*a

a Université de Lyon, Université Claude Bernard Lyon 1, Ecole Normale Supérieure de Lyon, Institut des Sciences Analytiques, 5 rue de la Doua, F-69100 Villeurbanne, France

b Université de Lyon, Université Claude Bernard Lyon 1, CNRS, Institut Lumière Matière, F69622, VILLEURBANNE, France

Corresponding Author

* marion.girod@univ-lyon1.fr

\section{Keywords}

Laser-induced dissociation, cysteine-containing peptides, chromophore derivatization 


\section{Abstract}

RATIONALE: Tandem mass spectrometry (MS/MS) is the pivotal tool for protein structural characterization and quantification. Identification relies on the fragmentation step of tryptic peptides in bottom-up strategy. Specificity of fragmentation can be obtained using laser induced dissociation (LID) in the visible range, after tagging of the targeted peptides with an adequate chromophore. Backbone fragmentation is required to obtain specific fragments and confident identification. We present herein a study of fragmentation patterns of chromophoretagged peptides in LID, showing the potential of LID methodology to provide the maximum of fragments for further identification and quantification.

METHODS: 401 cysteine-containing tryptic peptides coming from the human proteome were derivatizated on the thiol group of cysteine with a Dabcyl maleimide chromophore, which has a high photo-absorption cross section at $473 \mathrm{~nm}$. The derivatized peptides were then analyzed by LID at $473 \mathrm{~nm}$ on a Q Exactive instrument.

RESULTS: LID spectra present a characteristic fragment at $\mathrm{m} / \mathrm{z} 252.112$ for all precursors. This product ion arises from the internal dissociation of the dabcyl chromophore. Several peptide-backbone fragment ions are also detected. Results show the quasi absence of fragmentation at the cysteine site. This indicates that part of the energy must be redistributed across the entire system despite excitation initially localized at the chromophore. Indeed, the fragmentation mainly occurs at 3 to 5 amino acids from the derivatized cysteine residue.

CONCLUSIONS: LID of derivatized cysteine-containing peptides displays the initial fragmentation of the chromophore. As energy is redistributed all along the peptide sequence, fragmentation of the peptide backbone is also observed. Thus, LID of chromophore-tagged peptides produces adequate fragment ions, allowing both good sequence coverage for a greater confidence of identification, and a large choice of transitions for specific quantification. 


\section{Introduction}

Tandem mass spectrometry (MS/MS) is one of the most powerful and multi-skilled tools in the analytical area to provide structural information of a wide scope of molecules ${ }^{[1]}$. Applications include metabolomics or lipidomics, as well as proteomics with the direct identification of peptides and proteins in complex biological matrices based on their fragmentation behaviors. In an MS/MS study, like in any analytical approach, the confidence in identification is crucial. In all strategies, identification relies on the fragmentation step of tryptic peptides in bottom-up strategy, or intact proteins in top-down analysis. Indeed, each ionized polymer of amino acids will be fragmented uniquely after activation, generating typical fragments ( $\mathrm{a}, \mathrm{b}, \mathrm{c}$ and $\mathrm{x}, \mathrm{y}, \mathrm{z}$ ions). Comparison of the MS/MS spectra with databases, spectral libraries or manual treatment allows the direct identification of their sequence.

In proteomics, the gold standard used to fragment peptide ions is collision-induced dissociation (CID). Its primacy ensues from its robust performance, high efficiency and its well-known fragmentation pathways for protonated peptides ${ }^{[2-4]}$. In this slow-heating activation method, internal energy of precursor ions increases upon activation. This weak energy dissociation process tends to favors fragmentation via lower energy pathways and the cleavage of the most labile bonds. In the mobile proton model ${ }^{[5,6]}$, the ionizing protons, initially located at basic sites of the peptides, migrate to other sites to form backbone-amideprotonated species causing cleavages of the $\mathrm{C}-\mathrm{N}$ amide bonds via charge-induced mechanisms, generating b- and y-types ions. Although good sequence coverages are obtained, one inherent problem with CID is the importance of the neutral losses $\left(\mathrm{NH}_{3}\right.$ or $\left.\mathrm{H}_{2} \mathrm{O}\right)$, which provides limited structural information $\left.{ }^{[3,} 7\right]$. Moreover, the loss of post-translationalmodification (PTM) information, essential in the understanding of major biological process, is an issue. 
Electron-driven methods based on 'ion-electron' activation in electron capture dissociation $(\mathrm{ECD})^{[8,9]}$ and electron transfer dissociation $(\mathrm{ETD})^{[10,11]}$ overcome this limitation through formation of radical ion before fragmentation. In ECD and ETD, instead of an inert gas, precursor ions are activated by low energy electron $(\sim 1 \mathrm{eV})$ or electron-rich anions which are capable of transferring electrons ${ }^{[12]}$. After reception of an electron, the excited precursor ions becomes a radical and specifically break the $\mathrm{N}-\mathrm{C}_{\alpha}$ bonds via radical distribution and homolytic cleavage and yield $\mathrm{c}$ and $\mathrm{z}$ ions without abundant side-chain $\operatorname{loss}^{[13,14]}$. ECD provides adequate fragmentation while retaining the PTM groups.

As an alternative to 'ion-ion' activation technique, various photon-based methods have been described to extend information retrieval of peptides. For instance, the development of infrared multiphoton dissociation (IRMPD) ${ }^{[1,15,16]}$ using mostly $\mathrm{CO}_{2}$ laser $(10.6 \mu \mathrm{m})$ allows to produce vibrationally excited ions. When enough photons have been absorbed for the internal energy of the ion to cross the dissociation threshold, fragmentation can ensue after intramolecular vibrational energy redistribution (IVR) ${ }^{[17]}$. Low energy IRMPD selectively breaks the most liable amide $(\mathrm{C}-\mathrm{N})$ bonds and generates $\mathrm{b}$ and $\mathrm{y}$ ions, as well as neutral losses, similar to the traditional slow-heating CID method ${ }^{[18]}$. Activation and photodissociation of peptides with ultraviolet photons (UVPD) has been developed for characterizing peptides and leads to intense fragmentation patterns ${ }^{[19]}$. This technique can be employed with or without selecting chromophore which enable the excitation of all peptides without any sequence restriction. Absorption of photons provides enough energy to cause transition of ions to excited electronic states. Dissociation may occur directly from the excited states or ions may undergo internal conversion and intramolecular vibrational redistribution that may lead to product ions of the type more commonly observed upon collisional activation $^{[20]}$. In UVPD, protein and peptide cations predominately dissociate into $\mathrm{a} / \mathrm{x}$ ions and less frequently to $\mathrm{c} / \mathrm{z}$ and $\mathrm{b} / \mathrm{y}$ ions ${ }^{[19,21]}$. PTM groups are often preserved in UVPD. Different 
wavelengths such as 157,193 or $266 \mathrm{~nm}$ have been implemented in UVPD ${ }^{[22-29]}$. However, if the information obtained is very complete, the lack of specificity can be problematic in some proteomics approaches such as data independent analysis (DIA) when co-fragmentation occurs. In order to improve the specificity of the fragmentation method, the most obvious approach is to use a wavelength where peptides and proteins do not absorb naturally. The specific photodissociation is obtained after derivatization of the targeted molecule with an appropriate chromophore absorbing at this wavelength. This chromophore-tagging strategy combined with $351 \mathrm{~nm}$ UVPD has been explored in several recent applications ${ }^{[30-33]}$. Laser induced photo-dissociation (LID) in the visible range at $473 \mathrm{~nm}$ has also been developed for targeting only a subset of peptides. LID was developed for the specific detection of cysteinecontaining peptides via the grafting of a Dabcyl maleimide chromophore, which has a high photo-absorption cross section at $473 \mathrm{~nm}$, to the thiol group of cysteine. Indeed, cysteine is a rare amino acid with an occurrence of $2 \%$ but present in $89 \%$ of all human proteins, yielding little proportion of tryptic peptides containing one or more cysteine residues ${ }^{[34]}$. LID was implemented and validated on triple quadrupole instruments in Photo-Selected Reaction Monitoring (Photo-SRM) ${ }^{[35]}$ and a Q Exactive in All Ions Fragmentation ${ }^{[36]}$ (AIF) for the specific detection of cysteine-containing peptides.

In each case, the peptides are identified based on their fragmentation behavior. Backbone fragmentation is required to obtain sufficient sequence coverages ${ }^{[37]}$ and specific transitions for quantification in Multiple Reaction Monitoring (MRM) ${ }^{[38]}$. Here, we report the LID study at $473 \mathrm{~nm}$ of 401 derivatized cysteine-containing tryptic peptides coming from the human proteome. The LID pattern according to the peptide sequence and position of the cysteine residue was explored. The aim was to demonstrate the ability of LID to provide (i) the maximum of information to identify chomophore-tagged cysteine-containing proteotypic 
peptides, in discovery approaches and (ii) specific transitions for further quantification in MRM.

\section{Materials and methods}

\section{Chemicals and reagents}

Acetonitrile $(\mathrm{ACN})$, methanol $(\mathrm{MeOH})$ and water $\left(\mathrm{H}_{2} \mathrm{O}\right.$, LC-MS grade) were obtained from Fisher Scientific (Strasbourg, France). Formic acid (FA) (LC-MS grade), trypsin (type IX-S from Porcine Pancreas), tris(2-carboxyethyl)phosphine (TCEP), and ammonium acetate (AA) were purchased from Sigma-Aldrich (St Quentin-Fallavier, France). The chromophore DABCYL C2 maleimide was purchased from AnaSpec (Fremont, CA, USA). All cysteinecontaining tryptic peptides were purchased from ThermoFisher Scientific (Courtaboeuf, France) on 96 well plates as PEPotec SRM Grade 2 (unpurified).

\section{Instrumentation}

The experimental setup has been described in details elsewhere ${ }^{[36]}$. Briefly, it consists of a mass spectrometer coupled to a Visible continuous laser. The mass spectrometer is an hybrid quadrupole-orbitrap Q-Exactive mass spectrometer (ThermoFisher Scientific, San Jose, CA, USA) equipped with a HESI ion source coupled to a Surveyor HPLC-MS pump (Thermo Fisher Scientific, San Jose, CA, USA) and a PAL Auto-sampler (CTC Analytics, Switzerland). This instrument has been modified to allow visible laser irradiation of ions. A fused silica window was fitted on the rear of the HCD (High Collision Dissociation) cell to permit introduction of a laser beam. The detector plate, initially positioned at the exit of the HCD cell and on the laser beam trajectory, was removed with no impact on the instrument performance (resolution and sensitivity). The laser is a $473 \mathrm{~nm}$ continuous wavelength laser (cw) (ACAL BFI, Evry, France). Its output power was set to $400 \mathrm{~mW}$ and its beam diameter 
is $1.5 \mathrm{~mm}$ (divergence $1 \mathrm{mrad}$ ). The laser is slightly off axis in order to avoid photofragmentation in the C-trap.

\section{Sample preparation}

The 401 synthetic cysteine-containing tryptic peptides from human kinases were mixed in 50 pools at $400 \mu \mathrm{g} / \mathrm{mL}$ in $\mathrm{H}_{2} \mathrm{O} / \mathrm{ACN}(50 / 50)+0.5 \%$ of $\mathrm{FA}$ (8 peptides per pool on average). For building the spectral library, each pool were diluted at a concentration around $1 \mu \mathrm{g} / \mathrm{mL}$ into acidified water, mixed together in 1 pool, reduced, derivatized with a 3 -fold molar excess solution of TCEP (500 $\mu \mathrm{L}$ of a $1 \mathrm{mg} / \mathrm{mL}$ in $60 \mathrm{mM}$ AA solution) and a 5 -fold molar excess of DABCYL C2 maleimide chromophore in $\mathrm{MeOH}(500 \mu \mathrm{L}$ of a $1 \mathrm{mg} / \mathrm{mL}$ in $\mathrm{MeOH})$. The mixtures were stirred in the sonic bath then, stored in the dark for $4 \mathrm{~h}$ at room temperature. Subsequently, samples were desalted and concentrated using Oasis ${ }^{\mathrm{TM}}$ HLB 3 cc $(60 \mathrm{mg})$ reversed phase cartridges (Waters, Milford, MA, USA). The cartridges were conditioned with $1 \mathrm{~mL}$ of $\mathrm{MeOH}$ and then $1 \mathrm{~mL}$ of $\mathrm{MeOH} /$ water $(5 / 95, \mathrm{v} / \mathrm{v})$ containing $0.5 \% \mathrm{FA}$. After the loading, all cartridges were washed with $1 \mathrm{~mL}$ of $\mathrm{MeOH} /$ water $(5 / 95, \mathrm{v} / \mathrm{v})$ containing $0.5 \%$ FA and eluted with $1 \mathrm{~mL}$ of $\mathrm{MeOH}$ containing $0.5 \%$ FA. All samples were evaporated to dryness and resuspended in $100 \mu \mathrm{L}$ of $\mathrm{MeOH} /$ water $(95: 5, \mathrm{v} / \mathrm{v})$ containing $0.5 \%$ FA. All solutions were stored at $-20^{\circ} \mathrm{C}$ prior to use.

\section{HPLC separation}

HPLC separation was carried out on an XBridge C18 column $(3.5 \mu \mathrm{m}, 300 \mathrm{~A}, 2.1 \mathrm{~mm}$ i.d x $10 \mathrm{~cm}$ ) from Waters. The HPLC mobile phase consisted of water containing formic acid $0.1 \%$ $(\mathrm{v} / \mathrm{v})$ as eluent $\mathrm{A}$ and $\mathrm{ACN}$ containing formic acid $0.1 \%(\mathrm{v} / \mathrm{v})$ as eluent B. Elution was performed at a flow rate of $300 \mu \mathrm{L}$ min. The separation step a plateau with $15 \%$ of eluent B 
for $4 \mathrm{~min}$ followed by a linear gradient from $15 \%$ to $50 \%$ for $74 \mathrm{~min}$. The gradient was returned to the initial conditions and held there for $5 \mathrm{~min}$. The injection volume was $20 \mu \mathrm{L}$.

\section{Mass spectrometry operating condition}

Ionization was achieved using electrospray in positive ionization mode with an ion spray voltage of $4000 \mathrm{~V}$. The sheath gas and auxiliary gas (nitrogen) flow rates were set at 35 and 10 (arbitrary unit), respectively, with a HESI vaporizer temperature of $300^{\circ} \mathrm{C}$. The ion transfer capillary temperature was $300{ }^{\circ} \mathrm{C}$ with a sweep gas (nitrogen) flow rate at 5 (arbitrary unit). The S-lens RF was set at 50 (arbitrary unit). LID MS/MS spectra of doubly, triply and quadruple protonated species (according to the peptide size) were acquired in DDA (top10 analysis) and PRM (Parallel Reactions monitoring) modes for each pool of synthetic derivatized peptides. For DDA in full scan (FMS), the resolution was set to 35000 , the Automatic Gain Control (AGC) was $3.10^{6}$, the maximum injection time was set to $250 \mathrm{~ms}$. In $\mathrm{MS}^{2}$ the resolution was set to 17500 , the Automatic Gain Control (AGC) was $5.10^{6}$, the maximum injection time was set to $120 \mathrm{~ms}$ and the quadrupole isolation width was $2 \mathrm{Th}$. In PRM, the resolution was set to 17 500, the Automatic Gain Control (AGC) was $3.10^{6}$, the maximum injection time was set to $60 \mathrm{~ms}$ and the quadrupole isolation width was $2 \mathrm{Th}$. For LID experiments, the activation time was set to $25 \mathrm{~ms}$. In order to avoid collisions and CID contamination, HCD collision energy was set to the minimum $2 \mathrm{eV}$. For HCD experiments, the activation time was set to $3 \mathrm{~ms}$ and the normalized collision energy (NCE) was 28 .

\section{Results and discussion}

In order to examine the fragmentation pattern of LID induced at the peptide level, 401 cysteine-containing tryptic peptides were derivatized on the amino acid cysteine with the 
dabcyl chromophore. Different charge states were then fragmented using LID at $473 \mathrm{~nm}$ in a Q Exactive in PRM and DDA mode. All the obtained LID spectra were compiled and stored in the form of a spectral library in the Skyline software. The Skyline interface gives access and presents all the detected fragments from each derivatized peptide with their mass, charge, relative intensity, type and location on the peptide. For further investigation, only the MS/MS spectra of the charge state ion which gives the maximum of fragment ions were considered, for each peptide. Selected precursor ions were mostly doubly and triply protonated species, according to the size of the peptide. On this basis, we looked at the 401 different spectra of the spectral library and investigated a typical way of fragmentation in LID. Figure 1a shows the LID spectrum of the triply protonated chromophore derivatized ELGAALQGCLLR peptide, as an example. First, we were able to detect on each spectrum a characteristic high intensity fragment at $\mathrm{m} / \mathrm{z} 252.112$. This product ion arises from the internal dissociation of the dabcyl chromophore, which absorbs the visible light. This reporter ion is specific of the Dabcyl derivatized peptide but does not allow any characterization of the peptide sequence. However, several peptide-backbone fragment ions are also detected (Figure 1a). The observation of fragmentation channels associated with peptide backbone shows that part of the energy must be redistributed across the entire system despite excitation initially localized at the chromophore, which points to IVR and a global heating of the whole system prior to fragmentation ${ }^{[39]}$. The major obtained fragments are b- and y-type ions, with some consecutive water losses. They represent more than $90 \%$ of all the generated product ions indicating a predominant cleavage of the $\mathrm{C}-\mathrm{N}$ amide bonds during the LID fragmentation. Similar to CID or IRMPD, breaking of the most labile bonds is observed, which is consistent with IVR prior to fragmentation. Moreover, there are 2 types of fragment ions: those still containing the intact chromophore $\left(\mathrm{y}_{\mathrm{n}}{ }^{+}, \mathrm{b}_{\mathrm{n}}{ }^{+} \ldots\right)$ and those with the partial chromophore $\left(\mathrm{y}_{\mathrm{n}^{-}}\right.$ $251^{+}, b_{n}-251^{+}$), after internal photo-fragmentation of the latter. For comparison, HCD 
spectrum of the same derivatized peptide is shown Figure 1b. Overall, the same types of fragment ions are detected but with differences in relative intensities. Finally, all the ions detected in LID allow the identification of the cysteine-containing peptides with an average sequence covering of $82 \%$. Backbone fragments are obtained, that will allow specific transitions for quantification in MRM. We can also note that a fragmentation yield of $80 \%$ is obtained with $25 \mathrm{~ms}$ of activation time.

Next, in more details, we investigated the photo-fragmentation pattern according to the peptide sequence and the position of the chromophore derivatized cysteine amino acid. At this stage, it is important to note that only fragment ions with the intact chromophore were used for this statistical study. The practical reason for this is that the specific fragments which do not contain the intact chromophore $\left(\mathrm{y}_{\mathrm{n}}-251^{+}\right)$cannot be included in Skyline. First, localization on the peptide sequence of the 6 most intense fragment ions was identified and assigned to the corresponding amino acid (AA). Practically, for a peptide containing X AAs, $b_{n}$ ions were assigned to the $\mathrm{N}^{\text {th }}$ amino acid of the sequence, while the $\mathrm{y}_{\mathrm{n}}$ ions are assigned to the $\mathrm{X}-(\mathrm{n}-1)^{\text {th }}$ amino acid (see insert in Figure 2). The number of fragment ions associated to each AA was weighted by the total number of this AA in the 401 peptides (statistics on these total numbers are given in Supporting Information Table S1), to obtain the following ratio of fragments:

$$
\text { Fragmentation Ratio }(i)=\frac{\text { Number of fragments at the amino acid }(i)}{\text { Total number of amino acid }(i) \text { in the library }} X 100
$$

Figure 2 shows the ratio of fragment ions obtained for each amino acid (note that $\mathrm{K}$ and $\mathrm{R}$ are not presented here due to the tryptic nature of the peptides). As expected, most of the time, when a proline is present in a peptide sequence it generates a fragment at this location (76 $\%{ }^{[40]}$. A similar behavior is observed for the tryptophan residue $(69 \%)$. However, the most relevant behavior is the quasi absence of fragmentation at the cysteine location. This implies a 
process which promotes energy redistribution along the peptide sequence instead of a direct fragmentation on the chromophore derivatized cysteine. The depletion of fragmentation at the cysteine residues is more pronounced in LID, although it was also observed in CID $^{[41]}$. For all the other amino acids, no significant pattern could be extracted. It seems that AA belonging to the aromatic and aliphatic family (green and light green in Figure 2) are more prone to induce fragmentation at their side, while less fragments are obtained for the sulfurous and amide AAs (orange and red in Figure 2), which is also observed in $\mathrm{HCD}^{[41,42]}$. In order to avoid any bias in the result interpretation of amino acid specific fragmentation, the spatial distribution of each amino acid across the entire peptide pool was evaluated. For that, the relative position of each amino acid from the cysteine residue was calculated for all the 401 peptides (with the peptide size normalized to 1). Table S2 in the Supporting Information shows the mean position of each amino acid for the whole dataset of peptides. All the different amino acids are equally distributed and there is no specific amino acid which is always close or far away from the derivatized cysteine. The different fragmentation ratios observed for the different AA indicate that IVR is not total before fragmentation occurs ${ }^{[39]}$.

The presence of proline and tryptophan favors the fragmentation of the peptide at these sites. However, the total number of fragment ions along the peptide backbone is important for the identification. Thus, the energy redistribution mechanisms must be taken into account to enlighten the LID processes. In that way, the amino acid environment around the site of fragmentation was studied. For each fragment ion (assigned to an AA), the presence of the cysteine residue in the 2 AAs before and after the breaking site was searched. In average, 30 $\%$ of the observed fragments contain the derivatized cysteine at \pm 2 AAs from the fragmentation site. In order to evaluate the limit distance for the energetic redistribution, the position of the fragmentation from the derivatized cysteine was considered. For each size of peptides (8 to $20 \mathrm{AA}$, see Supporting Information), the number of detected fragment ions (b 
and y-types, representing more than $90 \%$ of the detected fragment ions) was plotted against the distance (i.e. number of AA) between the cysteine residue and the fragmentation site (Figure 3). The results show that the major distance from the fragmentation site to the cysteine is different according to the peptide size. The dispersion of energy in the system is not homogeneous. More fragment ions are detected at 2 AA from the cysteine for the peptides that contain 9 AA, while 6 AA separate the cysteine and the more frequent fragmentation site for the peptides containing $15 \mathrm{AA}$. The major distance of fragmentation from the cysteine residue increase with the peptide size, indicating that energy redistribution is favored for longer peptides. Interestingly, for peptides with 16 AA and more, 2 "maxima" of location of the fragmentation site are observed. One follows the increasing trend with the peptide size and the other one is closer to the cysteine residue. Thus, more fragment ions are observed all long the peptide backbone.

To have a more statistical distance value over the 401 peptides, the length of each peptide was normalized by 1 . Thus, the number of observed fragments was determined for different ranges of relative positions of the fragmentation site from the cysteine residue. This number was normalized to the total number of ions detected and was plotted against the relative distance between the cysteine and the fragmentation site (Figure 4 in blue). Here, a major relative distance from the fragmentation site to the cysteine is between 0.21 and $0.4 \mathrm{AAs}$ for $\mathrm{b}$ and $\mathrm{y}$ ions. The average size of the 401 peptides being $13.46 \mathrm{AAs}$, this indicates that the fragmentation mainly occurs at 3 to 5 amino acids from the derivatized cysteine residue in LID. However, fragmentation at longer relative distances from the cysteine is also observed for $35 \%$ of the detected fragment ions, which implies a more efficient energy redistribution after initial excitation location at the chromophore.

In order to validate the impact of the initial excitation of the derivatized cysteine on the LID fragmentation, the derivatized peptides were analyzed by HCD and the data processed the 
same way. The results indicate that the number of fragment ions detected as a function of the relative distance from the fragmentation site to the cysteine is more homogenous (Figure 4 in orange), especially at longer distances (between 0.41-0.80), than in LID. Thus, the effect of the derivatized cysteine on the fragmentation is less pronounced in $\mathrm{HCD}$, where the initial excitation is not specifically on the chromophore.

From this observation, we can pinpoint the importance of the chromophore derivatized cysteine location to enrich the LID spectrum. Thus, the number of $\mathrm{b}$ and $\mathrm{y}$ fragment ions and the associated sequence coverage was calculated for each peptide and evaluated regarding the position of the cysteine residue in the sequence. The size of the peptides was normalized at 1 and the relative position of the derivatized cysteine was obtained. Consequently, peptides can be clustered in 4 groups depending on the position of the cysteine in the peptide sequence: at the N-term (position $0-0.25$ ), in the middle left (position $0.26-0.5$ ), in the middle right (position 0.51-0.75) and at the C-term (position 0.76-1). Table 1 presents the averaged sequence coverages obtained for each groups. The results show that, a position in the middle of the sequence produces more fragments with an averaged sequence coverage of $73 \%$. In contrast, a peptide with a cysteine close to the $\mathrm{N}$ - or C-term will present a limited set of fragment ions in LID and a lower sequence coverage (averaged value of $62 \%$ ). Although, in this case, the sequence coverages are good enough for identification in bottom-up proteomic approaches, a narrow choice of transitions will be accessible for quantification in MRM.

Then, for the peptides with the better sequence coverages (93\% to $72 \%$ ) with the cysteine $\mathrm{AA}$ in position 0.26 to 0.75 , the nature of the other AA was investigated. The number of each type of AA present in these peptide sequences was calculated. For each amino acid, this value was again weighted by the total number of this AA in the 401 peptides. Figure 5 displays the normalized presence ratio of each AA in the peptides having the higher sequence coverages. 
The results indicate that optimal sequence coverages are associated to the presence of tryptophan, isoleucine, phenyalanine, serine and proline AAs in the peptide.

\section{Conclusions}

LID spectra were obtained for 401 Dabcyl derivatized cysteine-containing tryptic peptides. All the peptides show an intense specific fragment ion at $\mathrm{m} / \mathrm{z} 252.112$, arising from the internal dissociation of the dabcyl chromophore, which absorbs the visible light. Moreover, fragmentation of the peptide backbone is also observed, yielding mainly series of $\mathrm{b}$ and $\mathrm{y}$ ions. These structurally informative fragments contain or not the intact chromophore. Backbone fragmentation is not principally observed directly at the cysteine residue. This implies a process which promotes energy redistribution all along the peptide sequence between mainly 1 to 5 amino acids from the cysteine position. The LID pattern according to the peptide sequence and position of the cysteine residue was explored. A position of the cysteine in the middle of the sequence produces more fragments, in LID, due to energy redistribution on both sides of the cysteine location. This favors a better sequence coverage ( $>$ $70 \%)$ and a greater confidence for identification, even if adequate sequence coverages are obtained for other positions. Moreover, the longer the peptide, the more effective the energy redistribution. Thus, a peptide with 14 to 17 AA will present more fragment ions along the backbone. Furthermore, the presence of tryptophan, proline, phenyalanine, isoleucine and serine residues induces a higher fragmentation.

Finally, the results show the potential of LID to provide useful complete fragmentation of the backbone, which will allow confident identifications of chromophore-tagged tryptic peptides in further discovery approaches. Moreover, a large set of specific transitions could be accessible for specific quantification in MRM study. 


\section{Acknowledgements}

The authors would like to thank Dr. Luke MacAleese (ILM, CNRS et Université Lyon 1,

France) for valuable discussion and reading of this manuscript.

\section{References}

[1] Brodbelt, J. S., Ion Activation Methods for Peptides and Proteins. Analytical Chemistry 2016, 88, (1), 30-51.

[2] McLuckey, S. A., Principles of Collisional Activation in Analytical Mass-Spectrometry. Journal of the American Society for Mass Spectrometry 1992, 3, (6), 599-614.

[3] Paizs, B.; Suhai, S., Fragmentation pathways of protonated peptides. Mass Spectrometry Reviews 2005, 24, (4), 508-548.

[4] Shukla, A. K.; Futrell, J. H., Tandem mass spectrometry: dissociation of ions by collisional activation. Journal of Mass Spectrometry 2000, 35, (9), 1069-1090.

[5] Wysocki, V. H.; Tsaprailis, G.; Smith, L. L.; Breci, L. A., Special feature: Commentary - Mobile and localized protons: a framework for understanding peptide dissociation. Journal of Mass Spectrometry 2000, 35, (12), 1399-1406.

[6] Dongre, A. R.; Jones, J. L.; Somogyi, A.; Wysocki, V. H., Influence of peptide composition, gasphase basicity, and chemical modification on fragmentation efficiency: Evidence for the mobile proton model. Journal of the American Chemical Society 1996, 118, (35), 8365-8374.

[7] Wells, J. M.; McLuckey, S. A., Collision-induced dissociation (CID) of peptides and proteins. In Biological Mass Spectrometry, 2005; Vol. 402, pp 148-185.

[8] Zubarev, R. A., Electron-capture dissociation tandem mass spectrometry. Current Opinion in Biotechnology 2004, 15, (1), 12-16.

[9] Zubarev, R. A.; Haselmann, K. F.; Budnik, B.; Kjeldsen, F.; Jensen, F., Towards an understanding of the mechanism of electron-capture dissociation: a historical perspective and modern ideas. Eur. J. Mass Spectrom. 2002, 8, (5), 337-349.

[10] Syka, J. E. P.; Coon, J. J.; Schroeder, M. J.; Shabanowitz, J.; Hunt, D. F., Peptide and protein sequence analysis by electron transfer dissociation mass spectrometry. Proceedings of the National Academy of Sciences of the United States of America 2004, 101, (26), 9528-9533.

[11] Coon, J. J.; Shabanowitz, J.; Hunt, D. F.; Syka, J. E. P., Electron transfer dissociation of peptide anions. Journal of the American Society for Mass Spectrometry 2005, 16, (6), 880-882.

[12] Zubarev, R. A., Reactions of polypeptide ions with electrons in the gas phase. Mass Spectrometry Reviews 2003, 22, (1), 57-77.

[13] Zhurov, K. O.; Fornelli, L.; Wodrich, M. D.; Laskay, U. A.; Tsybin, Y. O., Principles of electron capture and transfer dissociation mass spectrometry applied to peptide and protein structure analysis. Chemical Society Reviews 2013, 42, (12), 5014-5030.

[14] Leymarie, N.; Costello, C. E.; O'Connor, P. B., Electron capture dissociation initiates a free radical reaction cascade. Journal of the American Chemical Society 2003, 125, (29), 8949-8958. 
[15] Brodbelt, J. S.; Wilson, J. J., Infrared Multiphoton Dissociation in Quadrupole Ion Traps. Mass Spectrometry Reviews 2009, 28, (3), 390-424.

[16] Crowe, M. C.; Brodbelt, J. S., Differentiation of phosphorylated and unphosphorylated peptides by high-performance liquid chromatography-electrospray ionization-infrared multiphoton dissociation in a quadrupole ion trap. Anal. Chem. 2005, 77, (17), 5726-5734.

[17] Payne, A. H.; Glish, G. L., Thermally assisted infrared multiphoton photodissociation in a quadrupole ion trap. Analytical Chemistry 2001, 73, (15), 3542-3548.

[18] Goolsby, B. J.; Brodbelt, J. S., Tandem infrared multiphoton dissociation and collisionally activated dissociation techniques in a quadrupole ion trap. Analytical Chemistry 2001, 73, (6), 12701276.

[19] Brodbelt, J. S., Photodissociation mass spectrometry: new tools for characterization of biological molecules. Chemical Society Reviews 2014, 43, (8), 2757-2783.

[20] Reilly, J. P., Ultraviolet Photofragmentation of Biomolecular lons. Mass Spectrom. Rev. 2009, 28, (3), 425-447.

[21] Cannon, J. R.; Carnmarata, M. B.; Robotham, S. A., et al., Ultraviolet Photodissociation for Characterization of Whole Proteins on a Chromatographic Time Scale. Anal. Chem. 2014, 86, (4), 2185-2192.

[22] Agarwal, A.; Diedrich, J. K.; Julian, R. R., Direct Elucidation of Disulfide Bond Partners Using Ultraviolet Photodissociation Mass Spectrometry. Anal. Chem. 2011, 83, (17), 6455-6458.

[23] Antoine, R.; Dugourd, P., Visible and ultraviolet spectroscopy of gas phase protein ions. J. Chem. Phys. 2011, 13, (37), 16494-16509.

[24] Diedrich, J. K.; Julian, R. R., Facile Identification of Phosphorylation Sites in Peptides by Radical Directed Dissociation. Anal. Chem. 2011, 83, (17), 6818-6826.

[25] Joly, L.; Antoine, R.; Broyer, M.; Dugourd, P.; Lemoine, J., Specific UV photodissociation of tyrosyl-containing peptides in multistage mass spectrometry. J. Mass Spectrom. 2007, 42, (6), 818824.

[26] Madsen, J. A.; Boutz, D. R.; Brodbelt, J. S., Ultrafast Ultraviolet Photodissociation at $193 \mathrm{~nm}$ and its Applicability to Proteomic Workflows. J. Proteome Res. 2010, 9, (8), 4205-4214.

[27] Madsen, J. A.; Xu, H.; Robinson, M. R., et al., High-throughput Database Search and Largescale Negative Polarity Liquid Chromatography-Tandem Mass Spectrometry with Ultraviolet Photodissociation for Complex Proteomic Samples. Mol. Cell. Proteom. 2013, 12, (9), 2604-2614.

[28] Shaw, J. B.; Li, W.; Holden, D. D., et al., Complete Protein Characterization Using Top-Down Mass Spectrometry and Ultraviolet Photodissociation. J. Am. Chem. Soc. 2013, 135, (34), 1264612651.

[29] Thompson, M. S.; Cui, W. D.; Reilly, J. P., Fragmentation of singly charged peptide ions by photodissociation at lambda=157 nm. Angewandte Chemie-International Edition 2004, 43, (36), 4791-4794.

[30] Aponte, J. R.; Vasicek, L.; Swaminathan, J., et al., Streamlining Bottom-Up Protein Identification Based on Selective Ultraviolet Photodissociation (UVPD) of Chromophore-Tagged Histidine- and Tyrosine-Containing Peptides. Anal. Chem. 2014, 86, (13), 6237-44.

[31] Cotham, V. C.; Wine, Y.; Brodbelt, J. S., Selective $351 \mathrm{~nm}$ Photodissociation of CysteineContaining Peptides for Discrimination of Antigen-Binding Regions of IgG Fragments in Bottom-Up Liquid Chromatography Tandem Mass Spectrometry Workflows. Anal. Chem. 2013, 85, (11), 55775585.

[32] O'Brien, J. P.; Pruet, J. M.; Brodbelt, J. S., Chromogenic Chemical Probe for Protein Structural Characterization via Ultraviolet Photodissociation Mass Spectrometry. Anal. Chem. 2013, 85, (15), 7391-7397.

[33] Robotham, S. A.; Horton, A. P.; Cannon, J. R.; Cotham, V. C.; Marcotte, E. M.; Brodbelt, J. S., UVnovo: A de Novo Sequencing Algorithm Using Single Series of Fragment lons via Chromophore Tagging and $351 \mathrm{~nm}$ Ultraviolet Photodissociation Mass Spectrometry. Analytical Chemistry 2016, 88, (7), 3990-3997. 
[34] Wang, S. H.; Zhang, X.; Regnier, F. E., Quantitative proteomics strategy involving the selection of peptides containing both cysteine and histidine from tryptic digests of cell lysates. Journal of Chromatography A 2002, 949, (1-2), 153-162.

[35] Enjalbert, Q.; Girod, M.; Simon, R., et al., Improved detection specificity for plasma proteins by targeting cysteine-containing peptides with photo-SRM. Anal. Bioanal. Chem. 2013, 405, (7), 23212331.

[36] Girod, M.; Biarc, J.; Enjalbert, Q., et al., Implementing visible $473 \mathrm{~nm}$ photodissociation in a Q-Exactive mass spectrometer: towards specific detection of cysteine-containing peptides. The Analyst 2014, 139, (21), 5523-30.

[37] Steen, H.; Mann, M., The abc's (and xyz's) of peptide sequencing. Nature Reviews Molecular Cell Biology 2004, 5, 699-711.

[38] Duncan, M. W.; Yergey, A. L.; Patterson, S. D., Quantifying proteins by mass spectrometry: The selectivity of SRM is only part of the problem. Proteomics 2009, 9, (5), 1124-1127.

[39] Bouakil, M.; Kulesza, A.; Daly, S.; MacAleese, L.; Antoine, R.; Dugourd, P., Visible Multiphoton Dissociation of Chromophore Tagged Peptides. Journal of the American Society for Mass Spectrometry 2017, DOI: 10.1007/s13361-017-1733-9.

[40] Vaisar, T.; Urban, J., Probing the proline effect in CID of protonated peptides. J. Mass Spectrom. 1996, 31, (10), 1185-1187.

[41] Michalski, A.; Neuhauser, N.; Cox, J.; Mann, M., A Systematic Investigation into the Nature of Tryptic HCD Spectra. Journal of Proteome Research 2012, 11, (11), 5479-5491.

[42] Shao, C.; Zhang, Y.; Sun, W., Statistical characterization of HCD fragmentation patterns of tryptic peptides on an LTQ Orbitrap Velos mass spectrometer. Journal of Proteomics 2014, 109, 2637. 


\section{Tables}

Table 1: Averaged sequence coverages obtained according to the relative cysteine position in the peptide sequence. Position 0 to 0.25 corresponds to the cysteine in the first quarter of the sequence, position 0.25 to 0.5 corresponds to the cysteine in the second quarter of the sequence, position 0.51 to 0.75 corresponds to the cysteine in the third quarter of the sequence and position 0.76 to 1 corresponds to the cysteine in the fourth quarter of the sequence.

\begin{tabular}{|c|c|}
\hline Relative cysteine position & Sequence coverage (\%) \\
\hline $0-0.25$ & 65.2 \\
\hline $0.26-0.50$ & 73.4 \\
\hline $0.51-0.75$ & 72.1 \\
\hline $0.76-1$ & 61.8 \\
\hline
\end{tabular}




\section{Figure captions}

Figure 1: MS/MS spectra of the triply protonated Dabcyl derivatized ELGAALQGCLLR peptide at $m / z 545.621$ in a) LID at $473 \mathrm{~nm}$ and b) HCD (NCE 28). The * indicates the precursor ion.

Figure 2: Fragmentation ratio for each amino acid. In green and light green are the aromatic and aliphatic AA, respectively; while in orange and red are the amide and sulfurous AA, respectively. The insert shows example of amino acid assignment for $\mathrm{y}_{8}$ and $\mathrm{b}_{5}$ ions.

Figure 3: Number of fragments detected according to the distance (i.e. number of AA) between the derivatized cysteine and the fragmentation site for each size of peptide.

Figure 4: Normalized number of fragments detected according to the relative distance between the derivatized cysteine and the fragmentation site (for the 401 peptides) in LID (blue) and HCD (orange).

Figure 5: Presence ratio of each amino acid in the peptides having sequence coverage of 93 $\%$ to $72 \%$. 